\title{
Aplikasi Jaringan Syaraf Tiruan Backpropagation untuk Meramalkan Tingkat Pengangguran Terbuka (TPT) di Provinsi Maluku
}

\author{
Yopi Andry Lesnussa ${ }^{1 *}$, Endro Risamasu ${ }^{2}$ \\ *e-mail: yopi_a_lesnussa@yahoo.com

\begin{abstract}
Program Studi Matematika, Fakultas Matematika dan Ilmu Pengetahuan Alam Universitas Pattimura
\end{abstract}

\begin{abstract}
Open Unemployment is a population of working age who does not have any work, who are actively looking for work. Backpropagation is an algorithm in artificial neural networks (ANN) that is used to predict or predict data. In this study, the Open Unemployment Rate will be predicted in Maluku Province. Based on the results of training analysis obtained an average forecasting success of $92.59 \%$ with the smallest error is MAPE $=0.0741 \%$. The result prediction of 5 next years shows the fluctuatif data from 2019 (9.5134) to 2023 (9.7924).
\end{abstract}

Keywords: Backpropagation, artificial neural networks, Open Unemployment Rate.

\begin{abstract}
ABSTRAK
Pengangguran terbuka (Open Unemployment) adalah penduduk usia kerja yang tidak mempunyai pekerjaan apapun, yang secara aktif mencari pekerjaan. Backpropagation adalah salah satu algoritma pada jaringan syaraf tiruan (JST) yang digunakan untuk meramalkan atau prediksi data. Dalam penelitian ini akan diramalkan Tingkat Pengangguran Terbuka (TPT) di Provinsi Maluku. Berdasarkan hasil analisis pelatihan diperoleh rata-rata keberhasilan permalan sebesar $92.59 \%$ dengan error terkecil yaitu MAPE $=0.0741 \%$. Hasil peramalan 5 tahun ke depan menunjukan data fluktuatif dari tahun 2019 (9.5134) sampai tahun 2023 (9.7924).
\end{abstract}

Kata Kunci: Backpropagtion, jaringan saraf tiruan, tingkat pengangguran terbuka

\section{PENDAHULUAN}

Pengangguran (Unemployment) menjadi salah satu permasalahan utama ketenaga kerjaan yang di hadapi negara berkembang, termasuk Indonesia. Pengangguran merupakan jumlah tenaga kerja dalam perekonomian yang secara aktif mencari pekerjaan tetapi belum mendapatkan pekerjaan(Sukirno 2003). Berdasarkan jam kerja pengangguran dibedakan menjadi tiga, antara lain pengangguran terselubung (Disguessed Unemployment), setengah pengangguran (Under Unemployment) dan pengangguran terbuka (Open
Unemployment) (Harfina S 2009), (Harfina S 2009) .

Penganggguran terbuka (Open Unemployment) adalah penduduk usia kerja yang tidak mempunyai pekerjaan apapun, yang secara aktif mencari pekerjaan. Tingkat pengangguran Terbuka (TPT) adalah persentase jumlah pengangguran terhadap jumlah angkatan kerja(Harfina S 2009), (BPS 2018). Meramalkan Tingkat pengangguran Terbuka (TPT) selalu menjadi bagian penting dalam mengetahui jumlah pengangguran. Dengan memanfaatkan 
kemajuan dan teknologi \& informasi yang semakin pesat saat ini, dapat dirancang sebuah sistem jaringan saraf tiruan (JST) dalam meramalkan Tingkat Pengangguran Terbuka (TPT) dengan menggunakan Metode Backpropagation (Puspitaningrum 2004).

Penelitian ini bertujuan untuk meramalkan tingkat pengangguran terbuka (TPT) di Provinsi Maluku menggunakan metode Backpropagation. Selanjutnya, penelitian ini diharapkan dapat menjadi alternatif untuk Meramalkan Tingkat pengangguran Terbuka (TPT) di Provinsi Maluku setiap tahunnya

\section{BAHAN DAN METODE}

Penelitian ini menggunakan data Tingkat Pengangguran Terbuka (TPT) Provinsi Maluku yang diperoleh dari Badan Pusat Statistika (BPS) Provinsi Maluku. Tipe penelitian adalah studi kasus, dengan mengaplikasikan Jaringan saraf tiruan Backpropagation untuk meramalkan atau memprediksi tingkat pengangguran terbuka selama 5 tahun ke depan dari Tahun 2005-2018 (selama 14 Tahun). Metode yang digunakan yaitu metode Jaringan Saraf Tiruan Backpropagation (Fausett 2017), (Puspitorini 2017). Berikut merupakan Flowchart atau bagan alir dari proses training dan testing pada metode Backpropagation (Lesnussa et al. 2018), (Lesnussa, Latuconsina, and Persulessy 2015):

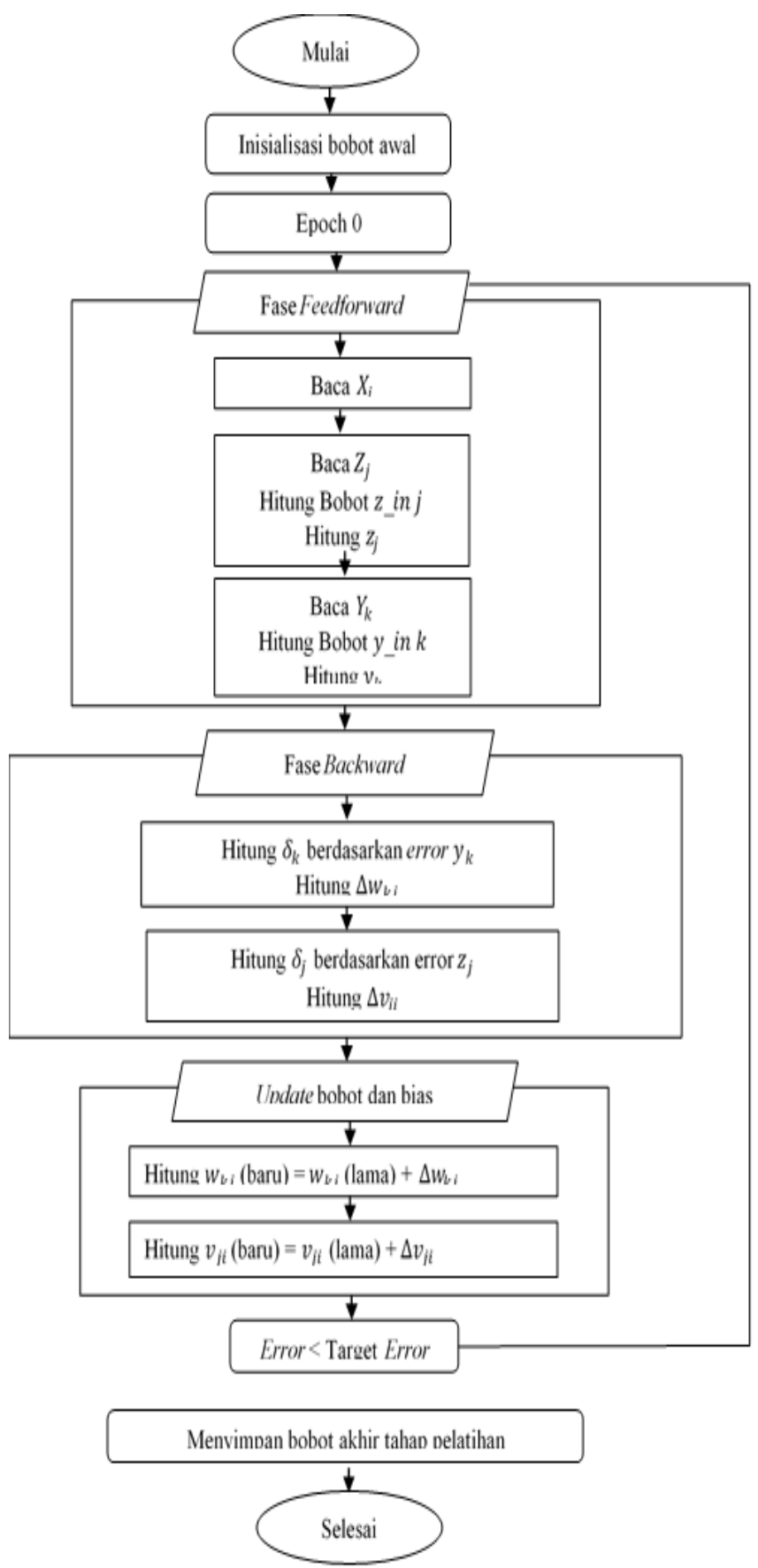

Gambar 1. Diagram Alir Proses Training pada Jaringan Backpropagation 


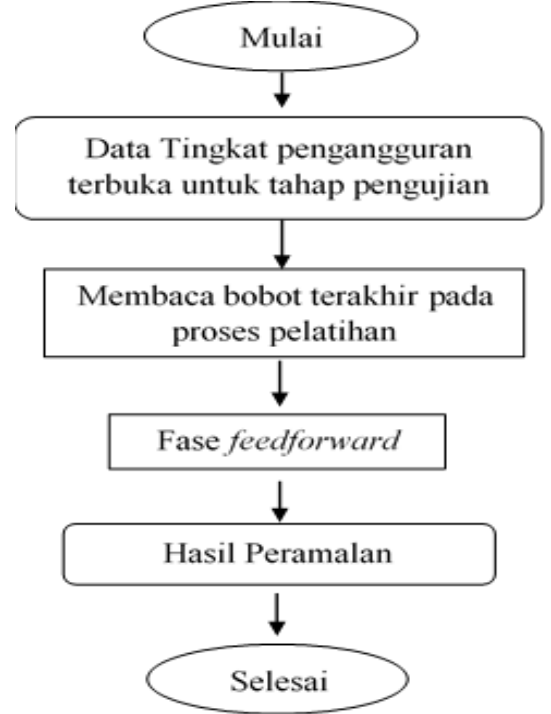

Gambar 2. Diagram Aliran Proses Testing pada Jaringan Backpropagation

\section{HASIL DAN PEMBAHASAN}

Dalam penelitian ini variabel yang digunakan adalah Tingkat pengangguran Terbuka (TPT) yang diperoleh dari Badan Pusat Statistik, masing-masing data merupakan rekap tahunan selama 14 tahun terakhir dari 2005-2018 pada Tabel 1. Data kemudian di normalisasi ke dalam selang $[0,1 ; 0,9]$ dengan mengunakan scalling minmax (Nasution, Khotimah, and Chamidah 2019), sebagai berikut:

$$
\mathrm{x}_{\mathrm{new}}=\frac{0.8\left(\mathrm{x}-\mathrm{x}_{\min }\right)}{\mathrm{x}_{\max }-\mathrm{x}_{\min }}+0.1
$$

Data yang telah dinormalisasi dapat dilihat pada Tabel 2.

Tabel 1. Tingkat Pengangguran Terbuka di Provinsi Maluku

\begin{tabular}{|c|c|c|}
\hline No & Tahun & Jumlah \\
\hline 1 & 2005 & 15.01 \\
\hline 2 & 2006 & 13.72 \\
\hline 3 & 2007 & 12.20 \\
\hline 4 & 2008 & 10.67 \\
\hline 5 & 2009 & 10.57 \\
\hline 6 & 2010 & 9.97 \\
\hline 7 & 2011 & 10.81 \\
\hline
\end{tabular}

\begin{tabular}{|c|c|c|}
\hline 8 & 2012 & 7.71 \\
\hline 9 & 2013 & 9.91 \\
\hline 10 & 2014 & 10.51 \\
\hline 11 & 2015 & 9.93 \\
\hline 12 & 2016 & 7.05 \\
\hline 13 & 2017 & 9.29 \\
\hline 14 & 2018 & 7.27 \\
\hline
\end{tabular}

Tabel 2. Tingkat Pengangguran Terbuka yang telah di normalisasi

\begin{tabular}{|c|c|c|}
\hline No & Tahun & Normalisasi \\
\hline 1 & 2005 & 0.9000 \\
\hline 2 & 2006 & 0.7704 \\
\hline 3 & 2007 & 0.6176 \\
\hline 4 & 2008 & 0.4638 \\
\hline 5 & 2009 & 0.4538 \\
\hline 6 & 2010 & 0.3935 \\
\hline 7 & 2011 & 0.4779 \\
\hline 8 & 2012 & 0.1663 \\
\hline 9 & 2013 & 0.3874 \\
\hline 10 & 2014 & 0.4477 \\
\hline 11 & 2015 & 0.3894 \\
\hline 12 & 2016 & 0.1000 \\
\hline 13 & 2017 & 0.3251 \\
\hline 14 & 2018 & 0.1221 \\
\hline
\end{tabular}

Pada tahap preprocessing, data yang telah di ditransformasi melalui proses normalisasi data diatas kemudian akan digunakan sebagai parameter masukan. Pada tahap ini data dibentuk menjadi, 2 variabel data time series dan 1 sebagai data target. Data ini kemudian dibuat pola atau skema pembagian data seperti pada Tabel 3 dan Tabel 4, sebagai berikut:

Tabel 3. Skema Pembagian data Untuk Prediksi

\begin{tabular}{|c|c|c|c|}
\hline No & X1 & X2 & Target \\
\hline 1 & Data & Data & Data \\
& 2005 & 2006 & 2007 \\
\hline 2 & Data & Data & Data \\
& 2006 & 2007 & 2008 \\
\hline$\ldots$ & $\ldots$ & $\ldots$ & $\ldots$ \\
\hline 11 & Data & Data & Data \\
& 2014 & 2015 & 2017 \\
\hline
\end{tabular}




\begin{tabular}{|l|l|l|l|}
\hline 12 & Data & Data & Data \\
& 2015 & 2016 & 2018 \\
\hline
\end{tabular}

Tabel 4. Data Tingkat pengangguran Terbuka (TPT) yang telah di normalisasi

\begin{tabular}{|c|c|c|c|}
\hline No & X1 & X2 & Target \\
\hline 1 & 0.9000 & 0.7704 & 0.6176 \\
\hline 2 & 0.7704 & 0.6176 & 0.4638 \\
\hline 3 & 0.6176 & 0.4638 & 0.4538 \\
\hline 4 & 0.4638 & 0.4538 & 0.3935 \\
\hline 5 & 0.4538 & 0.3935 & 0.4779 \\
\hline 6 & 0.3935 & 0.4779 & 0.1663 \\
\hline 7 & 0.4779 & 0.1663 & 0.3874 \\
\hline 8 & 0.1663 & 0.3874 & 0.4477 \\
\hline 9 & 0.3874 & 0.4477 & 0.3894 \\
\hline 10 & 0.4477 & 0.3894 & 0.1000 \\
\hline 11 & 0.3894 & 0.1000 & 0.3251 \\
\hline 12 & 0.1000 & 0.3251 & 0.1221 \\
\hline
\end{tabular}

\section{Proses Pelatihan dan Pengujian}

Alokasi pembagian data pelatihan (training) dan pengujian (testing) pada penelitian ini dibagi menjadi $70 \%$ data pelatihan dan $30 \%$ data pengujian. Sehingga dari total data pada Tabel 4, diperoleh data pelatihan sebanyak 8 data, sedangkan data pengujian sebanyak 4 data, seperti pada Tabel 5 dan Tabel 6, berikut:

Tabel 5. Data Pelatihan (Training)

\begin{tabular}{|c|c|c|c|}
\hline No & X1 & X2 & Target \\
\hline 1 & 0.9000 & 0.7704 & 0.6176 \\
\hline 2 & 0.7704 & 0.6176 & 0.4638 \\
\hline 3 & 0.6176 & 0.4638 & 0.4538 \\
\hline 4 & 0.4638 & 0.4538 & 0.3935 \\
\hline 5 & 0.4538 & 0.3935 & 0.4779 \\
\hline 6 & 0.3935 & 0.4779 & 0.1663 \\
\hline 7 & 0.4779 & 0.1663 & 0.3874 \\
\hline 8 & 0.1663 & 0.3874 & 0.4477 \\
\hline
\end{tabular}

Tabel 6. Data Pengujian (Testing)

\begin{tabular}{|l|l|l|l|}
\hline 1 & 0.3874 & 0.4477 & 0.3894 \\
\hline 2 & 0.4477 & 0.3894 & 0.1000 \\
\hline 3 & 0.3894 & 0.1000 & 0.3251 \\
\hline 4 & 0.1000 & 0.3251 & 0.1221 \\
\hline
\end{tabular}

Pada metode Backpropagation, arsitektur sebuah jaringan akan menentukan keberhasilan target yang akan dicapai karena tidak semua permasalahan dapat diselesaikan dengan arsitektur yang sama. Arsitektur jaringan yang diterapkan yaitu arsitektur jaringan multilayer. Salah satu metode yang masuk pada kategori arsitektur jaringan multilayer ini yaitu metode Backpropagation. Banyaknya Hidden layer ditentukan sendiri oleh pengguna sistem melalui cara percobaan konvergensi terbaik (trial and error), sampai diperoleh hasil konvergensi pelatihan yang paling baik (jumlah epoch terkecil). Parameter sistem masukan untuk pembentukan pola arsitektur jaringan, yaitu:

Net Size :

Input Layer: 2 neuron

Hidden Layer: 3-3-1 neuron

Output Layer: 1 neuron

Max epoch/iterasi : 500

Goal / Target (MSE): 0.000001

Dari hasil proses training data pada Tabel 5 diperoleh hasil training seperti pada Gambar 4, berikut: 


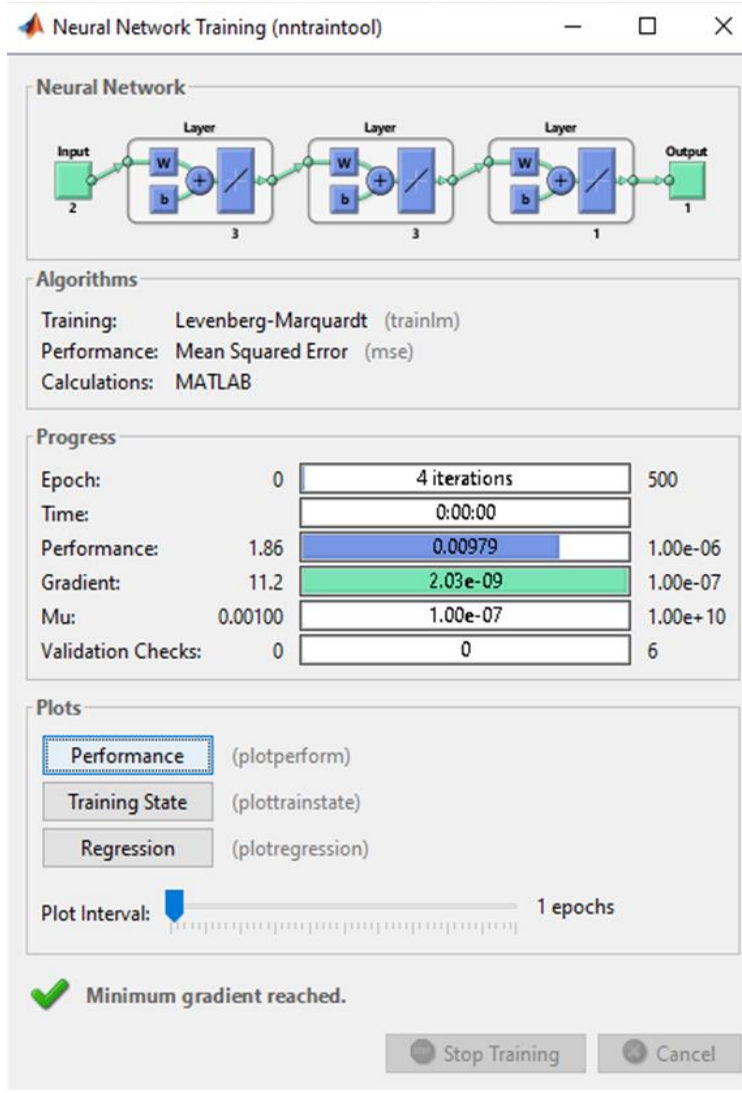

Gambar 4. Progress Neural Network Training

Berikut analisis data training yang dilakukan berdasarkan data pada Tabel 5, sebagai berikut:

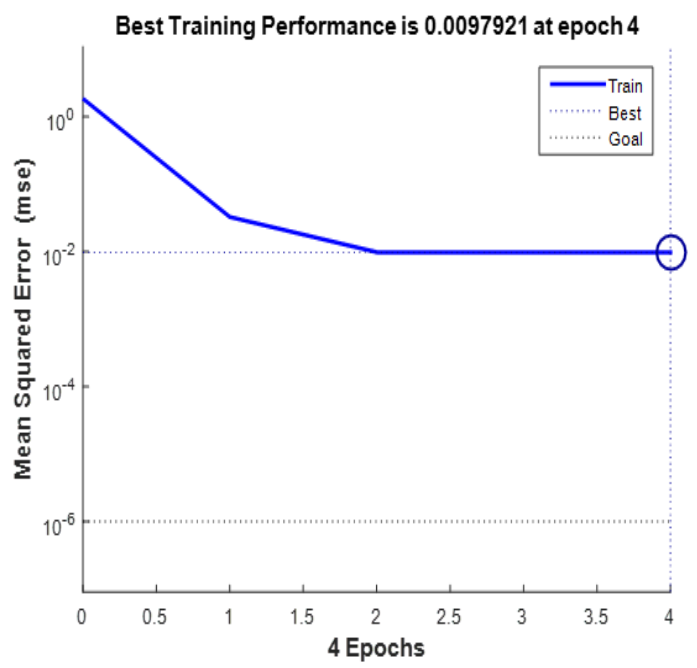

Gambar 5. Plot performance

Berdasarkan Gambar 4, dapat diketahui hasil dari proses JST backpropagation yang ditampilkan dalam bentuk grafik.
Pada Gambar 5, menunjukkan proses pembelajaran pada setiap epoch. Pada proses ini, iterasi dihentikan pada epoch ke- 4, karena batas epoch yang diinginkan sudah tercapai MSE $=0.097921$, dimana MSE ini merupakan MSE yang muncul ketika pelatihan selesai dilakukan sesuai dengan iterasi yang ditentukan.
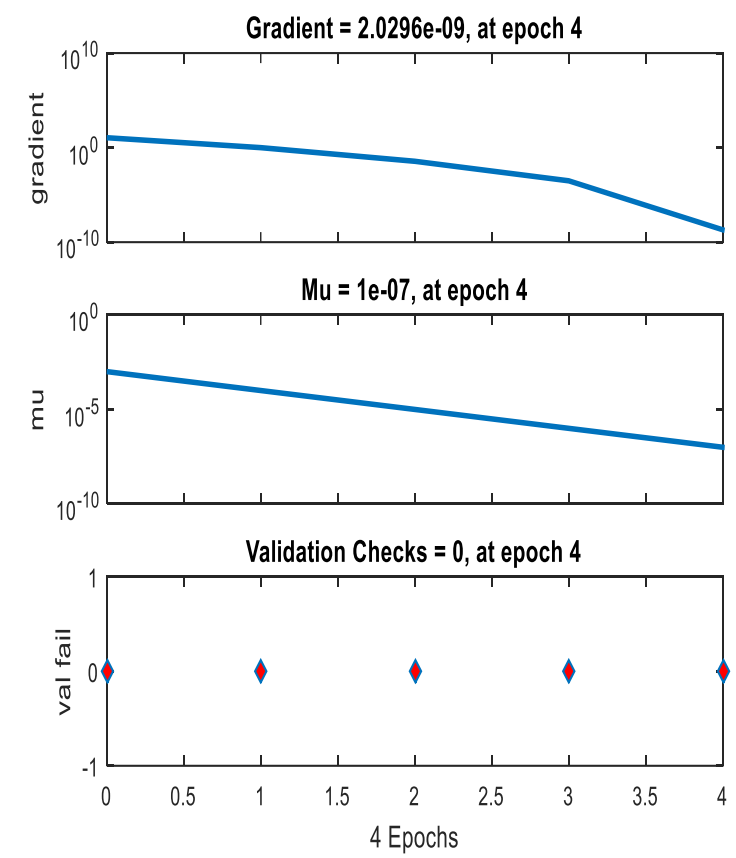

Gambar 6. Plot Train State

Gambar 6. menunjukkan train state dengan gradient sebesar $2.0288 \times 10^{9}$, mu sebesar $1 \times 10^{7}$ validation checks sebesar 0 pada iterasi ke 4 .

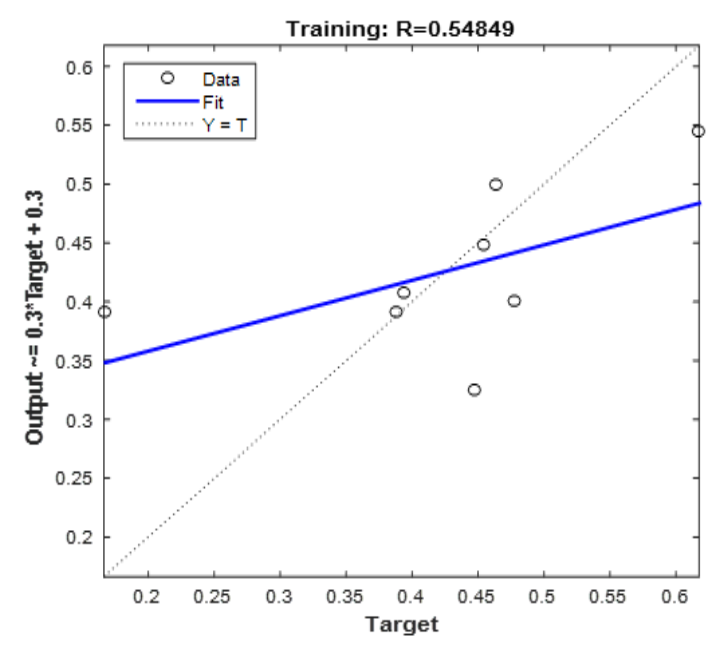

Gambar 7. Plot Regression 
Selanjutnya pada Gambar 7 . menunjukkan hubungan antara target dengan output jaringan pada data pelatihan. Dari pengujian pada data pelatihan untuk kecocokan antara output jaringan dengan target diperoleh koefisien korelasi (R) bernilai 0.54849 dimana untuk hasil terbaik adalah bernilai 1 , dengan koefisien korelasi sebesar itu menunjukkan bahwa jaringan sudah mampu memprediksi dengan baik sesuai dengan data yang ada.

Setelah melakukan pengujian (training) dan pelatihan (testing), didapat keluaran/output prediksi seperti pada bagian output training dan testing. Di dalam pelatihan nilai bobot dan bias awal ditentukan dengan bilangan acak kecil agar mendapatkan error yang minimum, agar hasil prediksi tidak berubah - ubah, karena jika tidak diberi batasan nilai bobot dan bias-nya maka output jaringannya akan berubah-ubah setelah membentuk jaringan jika dilakukan pelatihan berulang kali meskipun dengan lapisan tersembunyi yang sama. Adapun hasil pelatihan dan pengujian didapat sebagai berikut:

Tabel 7. Data Hasil Pelatihan (Menggunakan Tahun 2006-2014)

\begin{tabular}{|c|c|c|}
\hline No & $\begin{array}{c}\text { Target Tes } \\
\text { Asli }\end{array}$ & $\begin{array}{c}\text { Target Keluaran } \\
\text { JST }\end{array}$ \\
\hline 1 & 12.20 & 11.4744 \\
\hline 2 & 10.67 & 11.0275 \\
\hline 3 & 10.57 & 10.5195 \\
\hline 4 & 9.97 & 10.1110 \\
\hline 5 & 10.81 & 10.0420 \\
\hline 6 & 7.71 & 9.9446 \\
\hline 7 & 9.91 & 9.9436 \\
\hline 8 & 10.51 & 9.2875 \\
\hline
\end{tabular}

peramalan/prediksi menggunakan ratarata persentase eror absolut (MAPE) dengan rumus:

$$
M A P E=\frac{\frac{\sum\left|e_{i}\right|}{x_{a s l i}}(100 \%)}{n}
$$

Setelah dihitung diperoleh MAPE = 0.0741 atau dapat dikatakan rata-rata keberhasilan prediksi/peramalan sebesar $92.59 \%$.

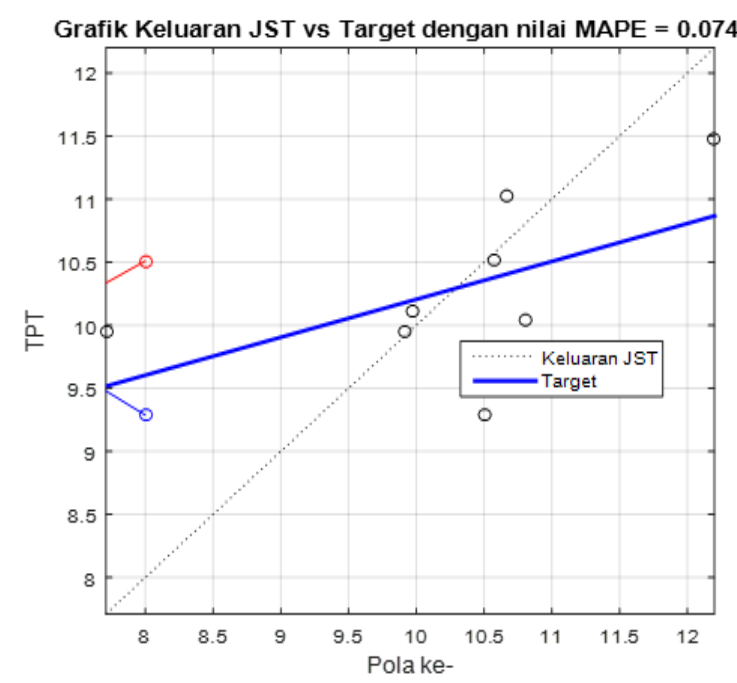

Gambar 8. Grafik Hasil Pelatihan (training) (Perbandingan Hasil Prediksi dengan Target Asli)

Pada Gambar 8, menunjukan perbandingan antara target asli dengan keluaran jaringan JST pada data training dengan learning rate $(\alpha)=0.1$.

Tabel 8. Data Hasil Pengujian (testing) (Menggunakan Tahun 2014-2018)

\begin{tabular}{|c|c|c|}
\hline No & $\begin{array}{c}\text { Target Tes } \\
\text { Asli }\end{array}$ & $\begin{array}{c}\text { Target } \\
\text { Keluaran JST }\end{array}$ \\
\hline 1 & 9.93 & 9.9074 \\
\hline 2 & 7.05 & 10.0234 \\
\hline 3 & 9.29 & 9.6656 \\
\hline 4 & 7.27 & 9.0701 \\
\hline
\end{tabular}

Ukuran akurasi peramalan/prediksi menggunakan rata-rata persentase eror absolut (MAPE) dengan rumus:

$$
M A P E=\frac{\frac{\sum\left|e_{i}\right|}{x_{a s l i}}(100 \%)}{n}
$$

Setelah dihitung diperoleh MAPE = 0.1780 atau dapat dikatakan rata-rata 
keberhasilan prediksi/peramalan sebesar $82.2 \%$.

Dari hasil pada tahapan pengujian pada Tabel 8. dan menggunakan jaringan yang sudah dilatih maka dapat dilakukan prediksi untuk Tingkat pengangguran Terbuka (TPT) 5 tahun ke depan dari tahun 2019, dapat diperoleh dari hasil pengolahan dengan Software Matlab, dengan hasil sebagai berikut:

Tabel 9. Hasil Peramalan Tingkat Pengangguran Terbuka (TPT) Provinsi Maluku

\begin{tabular}{|c|c|}
\hline Tahun & $\begin{array}{c}\text { Hasil Peramalan dengan } \\
\text { JST Backpropagation }\end{array}$ \\
\hline 2019 & 9.5134 \\
\hline 2020 & 9.1437 \\
\hline 2021 & 9.7058 \\
\hline 2022 & 9.6490 \\
\hline 2023 & 9.7924 \\
\hline
\end{tabular}

\section{KESIMPULAN}

Pada bagian hasil penelitian dapat disimpulkan bahwa rata-rata keberhasilan prediksi/peramalan sebesar $82.2 \%$, dengan MAPE $=0.1780$, diperoleh pada saat nilai learning rate 0.1 , dengan arsitektur jaringan hidden layer terbaik 33-1 neuron, epoch/iterasi: 500. Hasil peramalan/prediksi tingkat pengangguran menujukan fluktuasi dari tahun 2019 (9.5134) sampai tahun 2023 (9.7924).

\section{DAFTAR PUSTAKA}

Awan, Jehangir Ashraf and Onaiza Maqbool. 2010. "Application of Artificial Neural Networks for Monsoon Rainfall Prediction." in Proceedings - 2010 6th International Conference on Emerging Technologies, ICET 2010.

BPS. 2018. "Tingkat Pengangguran Terbuka." Https://Www.Bps.Go.Id.

Fausett, Laurene. 2017. Fundamentals Of

Neural Network Architectures,
Algorithms, and Applications.

Harfina S, Dewi. 2009. "Faktor-Faktor Yang Mempengaruhi Pengangguran Terselubung Di Perdesaan Jawa Tengah, Analisis Data Sakernas 2007." Jurnal Kependudukan Indonesia.

Hopfield, J. J. 1982. "Neural Networks and Physical Systems with Emergent Collective Computational Abilities." Proceedings of the National Academy of Sciences of the United States of America.

Lesnussa, Yopi A., S. Latuconsina, and E.

R. Persulessy. 2015. "Aplikasi Jaringan Saraf Tiruan Backpropagation Untuk Memprediksi Prestasi Siswa SMA (Studi Kasus: Prediksi Prestasi Siswa SMAN 4 Ambon)." Jurnal Matematika Integratif.

Lesnussa, Yopi Andry, C. G. Mustamu, F. Kondo Lembang, and M. W. Talakua. 2018. "Application Of Backpropagation Neural Networks In Predicting Rainfall Data In Ambon City." International Journal of Artificial Intelligence Research.

McCulloch, Warren S. and Walter Pitts. 1943. "A Logical Calculus of the Ideas Immanent in Nervous Activity." The Bulletin of Mathematical Biophysics.

Nasution, Darnisa Azzahra, Hidayah Husnul Khotimah, and Nurul Chamidah. 2019. "Perbandingan Normalisasi Data Untuk Klasifikasi Wine Menggunakan Algoritma KNN." Computer Engineering, Science and System Journal.

Puspitaningrum, Diyah. 2004. "Pengantar Jaringan Syaraf Tiruan." Jurnal Transformatika.

Puspitorini, Sukma. 2017. "Penyelesaian Masalah Traveling Salesman Problem Dengan Jaringan Saraf Self Organizing." Media Informatika.

Rumelhart, David E., Geoffrey E. Hinton, and Ronald J. Williams. 1986. 
"Learning Representations by BackPropagating Errors." Nature.

Smith, Jason and Robert N. Eli. 1995.

"Neural-Network Models of

Rainfall-Runoff Process." Journal of Water Resources Planning and Management.

Sukirno, Sadono. 2003. Pengantar Teori Mikroekonomi.

Vasudevan, Bintu G., Bhawani S. Gohil, and Vijay K. Agarwal. 2004. "Backpropagation Neural-NetworkBased Retrieval of Atmospheric Water Vapor and Cloud Liquid Water from IRS-P4 MSMR." IEEE Transactions on Geoscience and Remote Sensing. 